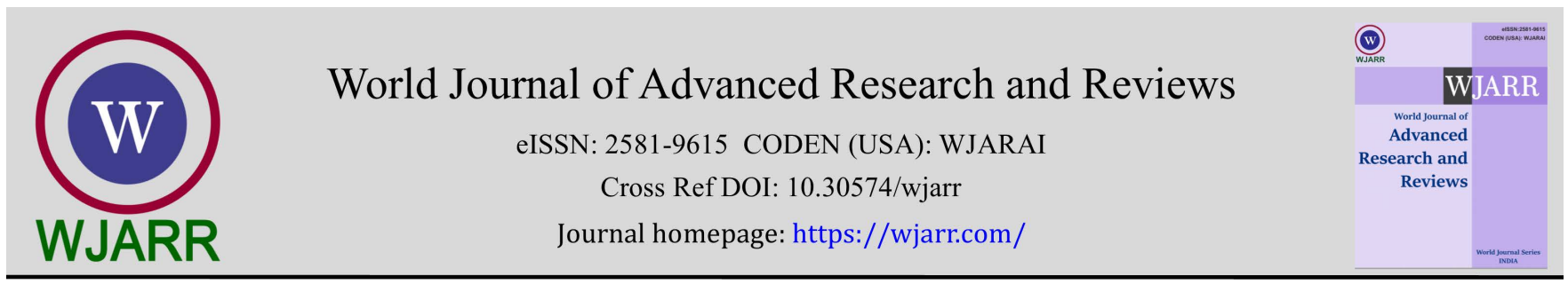

LETTER TO THE EDITOR

\title{
Pivotal role of community health physician: Nigeria as a case study
}

\author{
Briggs NCT ${ }^{1}$, Eli S ${ }^{2,}{ }^{*}$, Kalio DGB ${ }^{3}$ and Omodu PJ ${ }^{4}$ \\ ${ }^{1}$ Department of Community Medicine, Rivers State University. \\ ${ }^{2}$ Mother, Baby and Adolescent Care Global Foundation. \\ 3 Department of Obstetrics and Gynaecology, Rivers State University Teaching Hospital. \\ ${ }^{4}$ Department of Surgery, Rivers State University Teaching Hospital.
}

World Journal of Advanced Research and Reviews, 2021, 11(01), 051-052

Publication history: Received on 03 April 2021; revised on 01 July 2021; accepted on 04 July 2021

Article DOI: https://doi.org/10.30574/wjarr.2021.11.1.0208

\begin{abstract}
There are different school of thoughts or definitions of a "community" and a "community health physician/doctor". The Longman dictionary of contemporary English defines a community as a group of people living in the same place with a common interest. ${ }^{1}$ In the context of the World Health Organization, a community health doctor (CHD) or physician are members of a community chosen by the community. ${ }^{2}$ In our nation Nigeria these doctors are pivotal because of the peculiar role these doctors play. ${ }^{3}$ In some scenarios they play the role of public health doctors or epidemiologist but strictly there may be some subtle differences. ${ }^{4}$ They also play supervisory roles to community health nurses and community extension workes. ${ }^{4}$ Another school of thought defines a community health physician as a medical practitioner whose primary concern is the health status of the population within a defined geographic area who is usually responsible for assessment and evaluation of the community health needs and from the stand point of organization of health services to meet those needs. ${ }^{2}$ Furthermore, they are not under any obligation to provide primary healthcare, however, he/she renders care such as in some selected communicable diseases ${ }^{2}$ In majority of scenarios they are employed by government agency and their roles varies from one community to another..$^{3-4}$
\end{abstract}

A community health doctor serves as a bridge between other medical specialty such as paediatricians, obstetricians/gynaecologist, internist, dental surgeons, pathologist etc. ${ }^{5}$

The roles been played by the community health physicians (consultants are other cadre of doctors in this categories) are numerous. ${ }^{5}$ between the community and international organizations, ensure some base amenities are provided and so many other roles such asLet us look at how the community health doctor can be a bridge between the government and the local community. ${ }^{7}$ They can help drive policies in the area of health that favours the overall well-being of the community. ${ }^{8}$ Example of which help include advocacy against some harmful practices such as female genital mutilation, unsafe abortion, childhood marriage, gender inequity and inequality just to mention a few. ${ }^{9}$ These are harmful traditional practices that have grievous consequences on persons and the community at large. ${ }^{9}$

In rural communities, community health doctors working as public health doctor act as specialists that notify other specialists. ${ }^{10}$ In addition, they also synergize with paediatricians and epidiemologist in cases of childhood diseases such as cholera, dysentary to provide care to the affected communities. ${ }^{10,15}$ In this regard their roles may be complemented by international bodies such as the World Health Organization (WHO) and the United Nations Children Fund (UNICEF). ${ }^{12}$ In cases of epidemic and pandemic the community health doctors have useful roles to play in conjunction with international bodies to disseminate information and create awareness on such outbreaks for example the HIV/AIDS pandemic and the most recent the covid-19 pandemic of $2019 .{ }^{13}$ In addition, the community health physician are very vast in collection and analysis of data. ${ }^{12}$ In addition, such information are also used to prevent further spread

${ }^{*}$ Corresponding author: Eli S

Mother, Baby and Adolescent Care Global Foundation.

Copyright (C) 2021 Author(s) retain the copyright of this article. This article is published under the terms of the Creative Commons Attribution Liscense 4.0. 
of these diseases and drive policies to curb the further spread of specific disease conditions. ${ }^{14}$ Furthermore, the community health doctor complement specialist gynaecology, general surgery, urology etc to disseminate information in the prevention of cervical cancer, breast cancer a prostate cancer. ${ }^{15}$

The community health physician is also vast in research; in thecollection, interpretation and analysis data. ${ }^{13}$ If one can put it in this regard the community health are one of the bedrock in the training of the other specialist in the foundational aspect both at the undergraduate and post-graduate level in the field of research. ${ }^{13}$ In addition, they also cross into other disciplines outside the medical profession as well as government and international organizations in advisory roles in the prevention of both communicable and non-communicable disease conditions. ${ }^{13-14}$

\section{Conclusion}

The role of the community health doctor cannot be over-emphasized. They are invaluably to the community, the government, non-governmental organizations, international agencies, other medical specialist, religious bodies all and asundry especially in the area of disease prevention and driving of government policies in disease prevention.

\section{References}

[1] Longman dictionary of contemporary English. 2009;5:334.

[2] Van de Pas R, Kolie D, Delamon A et al. Health workforce development and retention in Guinea: a policy analysis post-Ebola. Hum Resour Health. 2019; 17:63.

[3] Scheffer R, Cormetto B, Tulenko K et al. Health workforce requirements for universal health coverage and sustainable development goals. Geneva: World Health Organization 2016.

[4] Kulmann E, Burau V, Correia T et al.A manager in the minds of doctors": a comparison of the modes of control in European hospitals. BMC Health Serv Res. 2013; 13: 246.

[5] Roberton T, Applegate I, Leferre AE et al. Initial experiences and innovations in supervising community health workers for maternal, newborn and child health in Murgoro region, Tanzania. Hum Health. 2015; 19:13.

[6] Aiduraywish SA. Sources of Health Information and Their Impacts on Medical Knowledge Perception Among the Saudi Arabian Population:Cross-Sectional Study. J Med Internet Res. 2020; 22(3): e14414.

[7] Akweongo P et al. It's a woman's thing: gender roles sustaining the practice of female genital mutilation among the Kassena-Nankana of northern Ghana. Reprod Health. 2021;18:52.

[8] Closing Practices: Department of Health. Https://health.ri.gov>about>closing (accessed 1/5/2021).

[9] The role of community health workers in COVID-19 vaccination. Https://apps.who.int>handle (accessed 1/5/2021).

[10] Community health doctors, List of high impact articles. Https://www.hilarispublisher.com> (accessed 1/5/2021).

[11] Division of community surgery - Massachusetts General Hospital. Https://www.massgeneral.org>about (accessed 1/5/2021).

[12] Ibama AS, Dennis P. Role of Community Health Practitioners In National Development:The Nigerian Situation International Journal of Clinical Medicine. 2016;07(07): 511 - 518. 